\title{
The Cause and Effect Relationship Study of the Police's Approval Rating Survey Tactics with DEMATEL Approach - A Case Study of Kaohsiung City Police Department
}

\author{
Tien-Chin Wang ${ }^{1}$, Bi-Chao Lee ${ }^{1,2, *}$ \\ ${ }^{1}$ Department of International Business, National Kaohsiung University of Science and Technology, Kaohsiung, Taiwan \\ ${ }^{2}$ Kaohsiung City Police Department, Kaohsiung, Taiwan
}

Email address:

tcwang $a$ kuas.edu.tw (Tien-Chin Wang), 1103405113 agm.kuas.edu.tw (Bi-Chao Lee)

${ }^{*}$ Corresponding author

\section{To cite this article:}

Tien-Chin Wang, Bi-Chao Lee. The Cause and Effect Relationship Study of the Police's Approval Rating Survey Tactics with DEMATEL Approach - A Case Study of Kaohsiung City Police Department. International Journal of Business and Economics Research. Vol. 7, No. 4, 2018, pp. 102-109. doi: 10.11648/j.ijber.20180704.14

Received: June 20, 2018; Accepted: July 20, 2018; Published: August 13, 2018

\begin{abstract}
Since 2004, the National Police Agency, the Ministry of the interior, Taiwan, has been conducting the survey on citizens' satisfaction with public safety. Every Police Department has been very concerned about this probe, and has exhausted all possible ways and tactics to raise people's approval rate on the police. After many years' efforts, pretty good results have been achieved. This paper uses DEMATEL as an evaluation method to understand the causal relationship between the criteria adopted in the polling and the polling results that have been achieved. First of all, the implementation tactics used by all precincts of the Kaohsiung City Police Department (KCPD) were classified into 3 criteria for promotion, 4 criteria for implementation, and 2 criteria for management, totaling 9 criteria that constituted 3 facets. Based on the Expert Survey Method (Delphi), questionnaires were handed out to officers who were responsible for the survey at all precincts of the KCPD to obtain their ideas, which were simplified into 2 criteria for promotion, 2 criteria for implementation, and 1 criterion for management, totaling 5 evaluation criteria. Then especially designed questionnaires based on the DEMATEL were used. Phone calls were made randomly to deputy directors of precincts, chiefs of administration, traffic and secretary sections, and 29 completed questionnaires were returned. A diagram of causal relationship was made through the calculation based on the DEMATEL. The analysis of the prominence, causal degree and arrow direction indicted that 2 criteria referred to as social media and PR activity which raised the prominence of the polling were important in elevating people's approval rate on the police. These two criteria were "affected criteria". Traffic safety, solving criminal cases, and improved serving attitude are criteria with lower correlation level but they are classified as causal criteria, which are the foundation of police work. The conclusion is that police departments should actually perform well in the "causing criteria", and then use social media and PR activity to make the public aware of their good performance, which will effectively raise people's satisfaction with the police performance.
\end{abstract}

Keywords: DEMATEL, Delphi, The Relation of Cause and Effect, Prominence

\section{Introduction}

Since 2004, the National Police Agency, the Ministry of the interior, Taiwan, has been conducting the survey on citizens' satisfaction with public safety. Every Police Department has been very concerned about this probe, and has exhausted all possible ways and tactics to raise people's approval rate on the police. After many years' efforts, pretty good results have been achieved. The survey was based on the questionnaires designed by Mr. Yinglong Yo of Taiwanese Public Opinion Foundation, and was carried out by Shun-shui Focus Survey Research Company which was responsible for random telephone interviews. The survey was conducted on 17-18 April 2017. The survey was conducted on people who were over 20 years old throughout the country with 1,082 effective samples whose error margin was $5 \%$ and confidence level was $2.98 \%$. A survey was carried out on 7 kinds of public servants' approval rates, in which police were 
given $74.1 \%$, followed by tax officers $55.8 \%$, military officers $55.6 \%$, general administrative officials $44.4 \%$, prosecutors $43.6 \%$, investigation bureau officers $38.5 \%$ and judges $24.5 \%$ at the bottom.

\subsection{The Tactics Adopted by the Precincts of the KCPD}

The various precincts of the KCPD had done a lot to boost people's satisfaction and, for that purpose, they had put forth implementation tactics. This paper collected the implementation tactics of various precincts and classified them into 3 criteria for promotion, 4 criteria for implementation, and 2 criteria for management, which constitute 3 facets and 9 criteria. (Table 1)

Table 1. Table of Analyzed Tactics Adopted by all Precincts of the KCPD to Boost their Approval Ratings.

\begin{tabular}{|c|c|c|}
\hline Facets & Criteria & Criteria contents \\
\hline \multirow{3}{*}{$\begin{array}{l}\text { Promotion } \\
\text { facet }\end{array}$} & Social media & Face book, line etc., micro-movies (U-Tube) \\
\hline & Conventional means & $\begin{array}{l}\text { Promotion of police work by LED subtitles, enhancement of good deeds, reporting excellent deeds, crime } \\
\text { prevention promotion in campus, survey promotion conducted with local involvement. }\end{array}$ \\
\hline & PR activity & $\begin{array}{l}\text { organizing citizens' tours of precincts, holding parents-children activities, policemen cycling at tourist } \\
\text { destinations, mobile police stations, activities jointly held by the police and citizens, utizisation of } \\
\text { community radio boradcast, and combining social charitable activities. }\end{array}$ \\
\hline \multirow{4}{*}{$\begin{array}{l}\text { Implementation } \\
\text { facets }\end{array}$} & $\begin{array}{l}\text { to protect the old, women, } \\
\text { children }\end{array}$ & $\begin{array}{l}\text { project for the protection of children, project for the protection of the old, project for increased patrol and } \\
\text { watch at midnight, project for making building safe, and project for household visits }\end{array}$ \\
\hline & traffic safety & $\begin{array}{l}\text { traffic safety promotion, traffic posts, crackdown on violation through persuasion, traffic accident } \\
\text { prevention }\end{array}$ \\
\hline & Crime prevention action & police teams that quickly respond to crime scenes, patrol and watch at criminal hot spots \\
\hline & Solving criminal cases & To increase crackdown on theft and drugs and elevate their clearance rates \\
\hline \multirow{2}{*}{$\begin{array}{l}\text { Management } \\
\text { facet }\end{array}$} & innovative police work & To innovate police work and things that are beneficial to the public \\
\hline & Improved serving attitude & $\begin{array}{l}\text { To make phone calls to ensure safety, to randomly make phone calls to police departments to see if police } \\
\text { answer the calls politely, to send out greeting cards to the public to maintain contact }\end{array}$ \\
\hline
\end{tabular}

\subsection{Selection Criteria by Delphi}

This paper used DEMATEL (Decision Making Trial and Evaluation Laboratory) to explore the causal relationship between all criteria and the rise of approval ratings. Based on the opinions of some scholars on the number of criteria to be used, this DEMATEL adopted 4-7 criteria in principle. 9 criteria were too many and should be simplified. As a result, 2 criteria were used for promotion, 2 criteria were used for implementation and 1 criterion was used for management. In principle, there were 5 criteria totally. Using the DEMATEL, 20 questionnaires were handed out to officers whose rank was above the commissioned rank of the second grade, 20 questionnaires were handed out to officers whose rank was the commissioned rank of the third grade, and 10 questionnaires were handed out to officers whose rank was below the commissioned rank of the fourth grade. The questionnaires used Satty's nine point scale as the following Table 2.

Table 2. 9-point scale questionnaires

\begin{tabular}{|c|c|c|c|c|c|c|c|}
\hline \multicolumn{8}{|c|}{$\begin{array}{l}\text { What is the score that you will give to the tactics called the promotion of police work through social media that is used to elevate people's } \\
\text { satisfaction with the police? }\end{array}$} \\
\hline 2 & 3 & 4 & 5 & 6 & 7 & 8 & 9 \\
\hline
\end{tabular}

Note: The score ranges from 1-9. Each number is round. When the number is small, the satisfaction is low; while the number is big, the satisfaction is high.

The returned effective questionnaires: there were 13 questionnaires returned by officers with a rank above the commissioned rank of grade 2 with an overall response rate of $65 \% ; 13$ questionnaires were returned by officers with a commissioned rank of grade 3 with an overall response rate of $65 \%$; and 6 questionnaires were returned by officers with a commissioned rank of grade 4 with an overall response rate of $60 \%$. After being averaged, the average score of all facets' criteria are as shown in table 3 .

Table 3. The table of the average score of all facets' criteria given by experts.

\begin{tabular}{lll}
\hline & social mmedia & 6.596 \\
Promotion facet & conventional means & 4.198 \\
& PR activity & 5.008 \\
& protection offerred to the old, women, and children & 5.044 \\
Implementation facet & traffic safety & 5.787 \\
& prevention against threats to public safety & 5.398 \\
clearance rates of criminal cases & 5.822 \\
Management facet & innovative police work & 4.811 \\
\hline
\end{tabular}


Based on the scores given by experts, the promotion facet adopts social media and PR activity criteria, implementation facet adopts traffic safety and clearance rates of criminal cases criteria, and the management facet adopts improved serving attitude criterion. Totally, there are 5 criteria used by this paper for analysis and the DEMETALE is used by this paper for study.

\section{Study methods}

\subsection{The DEMATEL (Decision Making Trial and Evaluation Laboratory)}

The DEMATEL method was built by the Geneva Research Centre of the Battelle Memorial Institute. It is especially practical and useful for visualizing the structure of complicated causal relationships with matrixs or digraphs.[1] From 1972 to 1979, DEMATEL could be used to resolve complex and difficult problems globally, and had been widely used as one of the best tools to solve the cause and effect relationship of various evaluation factors. (Hsiang-Chuan Liu, et. al., 2016). [2]

It can effectively obtain the causal relationship between criteria and the influence intensity by matrix operation, and establish a similar Structure Equation Modeling (SEM) of Network Relationship Map(NRM) (Liou, et. al., 2008). [3] The DEMATEL is to combine expert knowledge to explore the causal correlation between variables. [4] It can transform the complex system criterion into a clear structure model and the relationship between the cause group and the result Group is analyzed(Hsiao-Ming Chen, et. al., 2016). [5] It can handle internal dependencies of multiple criteria (Hori \& Shimizu, 1999). [6] It can find the relationship between criteria and dependency degree (Tamura, Akazawa,2005). [7] The core DEMATEL method comprises five calculation steps: (1) define the scale; (2) build a direct-relation matrix; (3) calculate a normalized matrix; (4) calculate a direct/indirect relationship matrix T. (Hsieh, Yi-Fang. et. al. 2016) [8] (5) draw causal relationship chart and give an explanation.

The numerical value of the direct-relation matrix is used to illustrate the influence degree and direction of the various elements in the system. Numbers indicate impact strength, Fontela and Gabus (1976) generate the comparison scale designed as four levels: 0 (no influence), 1 (low influence), 2 (some influence), and 3 (high influence). [9] The measuring symbol " + " is a positive influence, while "-" is a negative influence. (Table 4). Recently, in order to strengthen the analysis results, some scholars divide them into 5 levels. 0 (no influence), 1 (very low influence), 2 (low influence), 3 (high influence), and 4 (very high influence). (Ming-Lang Tseng, A causal and effect decision making model of service quality expectation using grey-fuzzy DEMATEL approach, 2009) [1], (Mavi, Reza Kiani, et. al., GSCM, green supply chain management). [10] Measuring the relationship between criteria requires that the comparison scale be designed as four level[9]: 0 (no influence), 1 (low influence), 2 (some influence), and 3 (high influence).

Table 4. Evaluating influence levels and symbol directions.

\begin{tabular}{llcl}
\hline $\begin{array}{l}\text { Measuring } \\
\text { scale }\end{array}$ & influence levels & $\begin{array}{l}\text { Measuring } \\
\text { symbol }\end{array}$ & $\begin{array}{l}\text { Influence } \\
\text { direction }\end{array}$ \\
\hline 0 & no influence & + & Positive influence \\
1 & low influence & - & Negative influence \\
2 & some influence & & \\
3 & high influence & & \\
\hline
\end{tabular}

\subsection{DEMATEL's Five Analysis Steps}

\subsubsection{Step 1. Define the Scale and Criteria}

Criteria are established in an organizational system for evaluating objectives and defining their definitions. The criteria organized can be formed through discussing, reviewing, brainstorming or questionnaires, etc.

\subsubsection{Step 2. to Build a Direct-Relation Matrix X}

Experts generating the direct-relation matrix create sets of the pairwise comparisons in terms of influence and direction between criteria. The initial data can be obtained as the direct-relation matrix that is a $n \times n$ matrix $X$, in which $x_{i j}$ is denoted as the degree to which the criterion $i$ affects the criterion $\mathrm{j}$. Assuming that there are 3 criteria to be evaluated, it can establish a direct-relationship matrix $\left[x_{\mathrm{ij}}\right]_{\mathrm{n} \times \mathrm{n}}=$ $\left[\begin{array}{lll}x_{11} & x_{12} & x_{13} \\ x_{21} & x_{22} & x_{23} \\ x_{31} & x_{32} & x_{33}\end{array}\right]$

\subsubsection{Step 3. Calculate a Normalized Matrix D}

The direct-relation matrix is normalized according to [step 2]. In vector $D$, the principle of the entire matrix $x$ is multiplied by s, and the formula is shown below.

$$
\begin{gathered}
\mathrm{S}=\frac{1}{\max _{1 \leq i \leq n} \sum_{j=1}^{n} x_{i j}} \text {, and } \\
\mathrm{D}=\mathrm{X} \times \mathrm{S}=\frac{x}{\max _{1 \leq i \leq n} \sum_{j=1}^{n} x_{i j}},\left[\mathrm{~d}_{\mathrm{ij}}\right]_{\mathrm{n} \times \mathrm{n}}
\end{gathered}
$$

\subsubsection{Step4. to Calculate a Direct/Indirect Relationship Matrix T}

After normalizing direct-relation Matrix D, the direct/indirect relationship matrix $\mathrm{T}$ is calculated, and the formula is:

$$
\mathrm{T}=\frac{D}{I-D} T=\left[\mathrm{t}_{\mathrm{ij}}\right]_{\mathrm{n} \times \mathrm{n}} \mathrm{i}, \mathrm{j}=1,2, \ldots, \mathrm{n}
$$

"I" is an identity matrix

\subsubsection{Step 5. Draw Causal Relationship Chart and Explain}

The $\left[\mathrm{t}_{\mathrm{ij}}\right]_{n \times n}(\mathrm{i}, \mathrm{j}=1,2, \ldots, \mathrm{n})$ is the critaria in $\mathrm{T}$, and the sum of each row and the sum of each column are expressed in $r_{i}$ and $c_{j}$ respectively, deriving the following formula:

The sum of rows is $\mathrm{R}=\mathrm{r}_{\mathrm{n} \times 1}=\left[\sum_{j=1}^{n} \mathrm{t}_{i j}\right]_{n \times 1}^{t}$

The sum of columns is $\mathrm{C}=\mathrm{c}_{1 \times \mathrm{n}}=\left[\sum_{i=1}^{n} \mathrm{t}_{i j}\right]_{1 \times \mathrm{n}}^{t}$

$r_{i}$ : The sum of the other criterion that is influenced (including direct and indirect effects) by criterion $i$.

$c_{j}$ :The sum of the affected other criterion is the result of criterion $\mathrm{j}$. 
The sum of rows and the sum of columns are separately denoted as vector $\mathrm{D}$ and vector $\mathrm{R}$ in the following equations. The horizontal axis vector $(\mathrm{D}+\mathrm{R})$ named"Prominence" is made by adding $\mathrm{D}$ to $\mathrm{R}$, which reveals how much importance the criterion has. Similarly, the vertical axis (D- R) named "Relation" is made by subtracting D from R, which may group criteria into a cause group. Or, if the $(D-R)$ is negative, the criterion is grouped into the effect group. Therefore, the causal diagram can be acquired by mapping the dataset of the $(\mathrm{D}+\mathrm{R}, \mathrm{D}-\mathrm{R})$, providing valuable insight for making decisions. (Ching-Lan Tsai, 2015) [11]

\section{Empirical Research}

\subsection{To Define Criteria and to Probe Scales}

This research is based on the criteria of the implementation tactics adopted by all precincts of the KCPD. The number of criteria is 4-7 as advised by scholars. This research adopts the criteria that evaluate facets and do critical evaluation as shown in Table 5. 5 criteria are used and the evaluation framework is shown in the following diagram.

Table 5. Explanation of the criteria used to elevate the approval ratings given to police departments.

\begin{tabular}{|c|c|c|}
\hline Facets & Criteria & Criteria contents \\
\hline \multirow[t]{2}{*}{ Promotion facet } & Social media & Face book, line etc., micro-movies (U-TUBE) \\
\hline & PR activity & $\begin{array}{l}\text { organizing citizens' tours of precincts, holding parents-children activities, policemen cycling at } \\
\text { tourist destinations, mobile police stations, activities jointly held by the police and citizens, } \\
\text { utilization of community radio broadcast, and combining social charitable activities }\end{array}$ \\
\hline \multirow{2}{*}{ Implementation facet } & Traffic safety & $\begin{array}{l}\text { traffic safety promotion, traffic posts, crackdown on violation through persuasion, and traffic } \\
\text { accident prevention }\end{array}$ \\
\hline & Solving criminal cases & $\begin{array}{l}\text { to increase the clearance rate of serious crime such as theft and drug offences, to innovate police } \\
\text { work and to do things beneficial to the public }\end{array}$ \\
\hline Management facet & Improving serving attitude & $\begin{array}{l}\text { to make phone calls to ensure safety, to randomly make phone calls to police departments to see if } \\
\text { police answer the calls politely, to send out greeting cards to the public to maintain contact }\end{array}$ \\
\hline
\end{tabular}

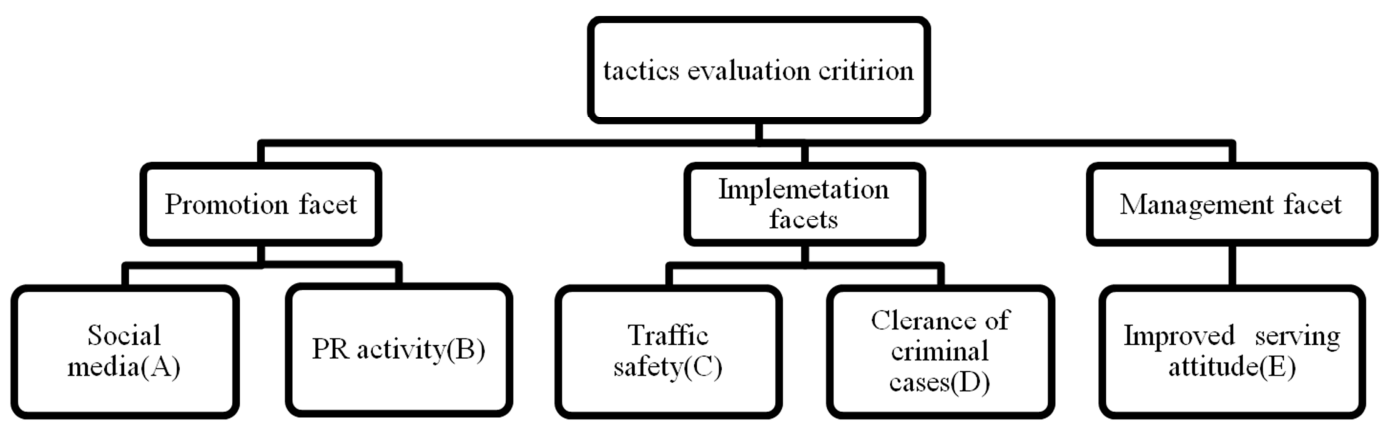

Figure 1. Diagram of tactics evaluation criterion.

\subsection{Questionnaire Design and Probe}

\subsubsection{Questionnaire Design}

Performance evaluation is a decision-making issue of multiple criteria. It is hoped that this research can find critical criteria that can elevate people's satisfaction in polling which can be aided by experienced officers who are in charge of surveys in their police departments and offer their professional judgment and experience. As a result, it can ascertain the causal relationship between criteria. This research uses DEMATRL to measure the relationship between criteria and adopts the comparison scale that is divided into four levels: 0 (no influence), 1 (low influence), 2 (influence), and 3 (high influence). A positive number has a positive influence and a negative number has a negative influence. In the beginning of the survey, the callers who conduct the survey will tell the person surveyed about the means used to determine the comparison scale. In order to meet the spirit of a genuinely professional polling, the surveyed people have an education above a two year college with a police rank above a commissioned rank of grade 2 who is a deputy director, a chief of the administrative or inspector sections and a chief secretary of the secretary office with over 16 years of seniority. Based on the criteria, questions are asked to determine their influence degree and direction. (Table 6)

Table 6. The influence of the criteria used in the questionnaire.

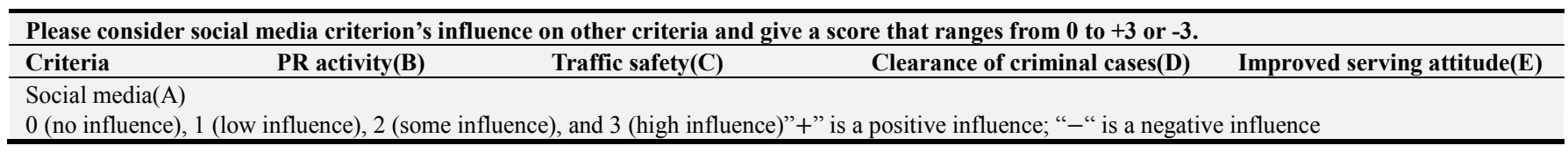

\subsubsection{Explanation of Questionnaire Questions}

Matters concerning the questionnaire:
1. The way the questionnaire is conducted: This research uses random phone calls to conduct the polling through 
questionnaires transmitted by fax.

2. The time used to conduct the polling: 29 questionnaires were sent out on 29-30 November 2017.

3. The officers who responded to the questionnaires: The deputy directors, the chiefs of the administrative and inspector sections and the chief secretaries of the secretary offices of all precincts of the KCPA, who were in charge of conducting pollings with at least a 2 -year college degree and 16 years of seniority, were asked questions in the questionnaire.

4. The number of questionnaires issued: This research totally issued 29 questionnaires (see index 1), and they were all effective (see Table 7). (Li-Hsing Hoa, et al. 2012). [12]

Table 7. Basic personal information of the respondents to the questionnaire.

\begin{tabular}{llll}
\hline \multirow{2}{*}{ Sex } & Male & Female & \\
\cline { 2 - 4 } & 26 & 3 & Above graduate \\
Educational & 2-year college & University & school \\
level & 3 & 13 & 10 \\
& $36-45$ years old & $46-55$ years old & over 56 years old \\
Age & 5 & 21 & 3 \\
& $10-15$ Years & $16-20$ Years & Over 21 years \\
Seniority & 0 & 6 & 23 \\
& 7 deputy directors, 22 chiefs and chief secretaries, totally \\
\hline
\end{tabular}

\subsection{Data Processing and Analysis}

According to the above-mentioned research framework and calculation steps of the DEMATEL, the criteria of the 29 returned effective questionnaires were calculated and the calculation steps are explained as follows:

\subsubsection{Step 2: Build a Direct-Relation Matrix $X$}

29 effective questionnaires $\left(\mathrm{H}_{1} \sim H_{29}\right)$ have their criteria's direct-relation matrix $\left(\mathrm{X}_{1} \sim X_{5}\right)$ displayed as follows: (Table 8)

$$
\mathrm{X}=\left[\begin{array}{ccccc}
0 & 1.6897 & 1.6207 & 1.3448 & 1.5172 \\
1.5172 & 0 & 1.2069 & 0.9655 & 1.1724 \\
1.5172 & 1.2759 & 0 & 0.48 & 1.1034 \\
1.6897 & 0.8621 & 0.4138 & 0 & 0.9310 \\
1.5862 & 1.5172 & 0.9310 & 0.7241 & 0
\end{array}\right]
$$

3.3.2. Step 3: Calculate a Normalized Matrix D

$\mathrm{X} \times \mathrm{S}$ to build the normalized direct-relation matrix (D) as Table 9 .

$$
\mathrm{S}=\frac{1}{\text { the maximum of rows }(6.1724)}
$$

Table 8. The direct-relation matrix $X$

\begin{tabular}{lllllll}
\hline Criteria & A & B & C & D & E & S $=$ \\
\hline A & 0.0000 & 1.6897 & 1.6207 & 1.3448 & 1.5172 & 6.1724 \\
B & 1.4483 & 0.0000 & 1.2069 & 0.9655 & 1.1724 & 4.7931 \\
C & 1.5172 & 1.2759 & 0.0000 & 0.4828 & 1.1034 & 4.3793 \\
D & 1.6897 & 0.8621 & 0.4138 & 0.0000 & 0.9310 & 3.8966 \\
E & 1.5862 & 1.5172 & 0.9310 & 0.7241 & 0.0000 & 4.7586 \\
\hline
\end{tabular}

A: Social media; B: PR activity; C: Traffic safety; D: Clearance of criminal cases; E: Improved serving attitude
Table 9. The normalized direct-relation matrix (D).

\begin{tabular}{llllll}
\hline $\mathbf{D}=\mathbf{X} \times \mathbf{S}$ & $\mathbf{A}$ & $\mathbf{B}$ & $\mathbf{C}$ & $\mathbf{D}$ & $\mathbf{E}$ \\
\hline $\mathrm{A}$ & 0.0000 & 0.2737 & 0.2626 & 0.2179 & 0.2458 \\
$\mathrm{~B}$ & 0.2346 & 0.0000 & 0.1955 & 0.1564 & 0.1899 \\
$\mathrm{C}$ & 0.2458 & 0.2067 & 0.0000 & 0.0782 & 0.1788 \\
$\mathrm{D}$ & 0.2737 & 0.1397 & 0.0670 & 0.0000 & 0.1508 \\
$\mathrm{E}$ & 0.2570 & 0.2458 & 0.1508 & 0.1173 & 0.0000 \\
\hline
\end{tabular}

A: Social media; B: PR activity; C: Traffic safety; D: Clearance of criminal cases; E: Improved serving attitude

\subsubsection{Step 4: Calculate a Direct/Indirect Relationship Matrix $T$}

$$
\begin{aligned}
T=\frac{D}{I-D}, T & =\left[t_{i j}\right]_{n \times n} i, j=1,2, \ldots, n .(T \\
= & \left.D \times(I-D)^{-1}\right)
\end{aligned}
$$

Build a unit matrix as table 10, calculate the I-D value as table 11, and obtain $\mathrm{T}$ as table 12 .

Table 10. I means unit matrix.

\begin{tabular}{llllll}
\hline Criteria & A & B & C & D & E \\
\hline A & 1 & 0 & 0 & 0 & 0 \\
B & 0 & 1 & 0 & 0 & 0 \\
C & 0 & 0 & 1 & 0 & 0 \\
D & 0 & 0 & 0 & 1 & 0 \\
E & 0 & 0 & 0 & 0 & 1 \\
\hline
\end{tabular}

A: Social media; B PR activity; C: Traffic safety; D: Clearance of criminal cases; E: Improved serving attitude

Table 11. I-D value.

\begin{tabular}{llllll}
\hline Criteria & A & B & C & D & E \\
\hline A & 1.0000 & -0.2737 & -0.2626 & -0.2179 & -0.2458 \\
B & -0.2346 & 1.0000 & -0.1955 & -0.1564 & -0.1899 \\
C & -0.2458 & -0.2067 & 1.0000 & -0.0782 & -0.1788 \\
D & -0.2737 & -0.1397 & -0.0670 & 1.0000 & -0.1508 \\
E & -0.2570 & -0.2458 & -0.1508 & -0.1173 & 1.0000 \\
\hline
\end{tabular}

A: Social media; B: PR activity; C: Traffic safety; D: Clearance of criminal cases; E: Improved serving attitude

Table 12. The total-relation matrix (T).

\begin{tabular}{lllllll}
\hline T $=$ & A & B & C & D & E & Avg. \\
\hline A & 0.9250 & 1.0554 & 0.9067 & 0.7670 & 0.9514 & $\mathbf{0 . 7 5 8 8}$ \\
B & 0.9487 & 0.6909 & 0.7390 & 0.6205 & 0.7801 & \\
C & 0.9099 & 0.8249 & 0.5473 & 0.5348 & 0.7376 & \\
D & 0.8663 & 0.7154 & 0.5629 & 0.4226 & 0.6640 & \\
E & 0.9668 & 0.8952 & 0.7141 & 0.5972 & 0.6254 & \\
\hline
\end{tabular}

A: Social media; B: PR activity; C: Traffic safety; D: Clearance of criminal cases; E: Improved serving attitude

\subsubsection{Step 5: Draw Causal Relationship Chart and Give an Explanation}

In order to present prominent causal relationships, scholars tend to set a threshold to control the numerical value that can affect the total influence of $\mathrm{T}$ Matrix. They delete the numerical value that is below the threshold and replace it with" $0 "$, that presents a more prominent causal relationships (influence direction), in which the threshold is set by using the quartile deviation (Chih-Hsien Fan, et. al., 2009). [13] That affects the total relationship matrix, expert decision 
making (Gwo-Tsuen Jou, et. al. 2014) [14], or that is the arithmetical average number (Ching-Lan Tsai, 2015). [11] The matrix average that takes the mean and standard deviation (Chunguang Bai, Joseph Sarkis, 2013) [15], in which the numbers that are below the standard value are deleted from the matrixs (liker Goluck, Adil Bavkasoglu 2016)[4]. This research's threshold is based on arithmetical average numbers whose value is 0.7588 , by which the virtual simplified matrix is obtain as table 13 . To add together all rows and columns of the virtual simplified matrix $\mathrm{T}$, which is taken from the total influence relation matrix, it will be able to obtain the total sum of all columns (value R) and the total sum of all rows (value $\mathrm{C}$ ).

Calculate the value of $(\mathrm{r}+\mathrm{c})$ as table 14. Based on the numerical value on table 13 , use $(\mathrm{r}+\mathrm{c})$ as the horizontal axis $\mathrm{x}$ and ( $\mathrm{r}-\mathrm{c}$ ) as the vertical axis $\mathrm{y}$, select matrix 5's criteria preserved numerical value and draw arrow symbols and influence directions on the coordinate according to its figures, which maybe either one-way influence or two-way influence as shown in (Figure 2).
Table 13. Virtual simplified matrix $T$.

\begin{tabular}{llllll}
\hline & A & B & C & D & E \\
\hline A & 0.9250 & 1.0554 & 0.9067 & 0.767 & 0.9514 \\
B & 0.9487 & 0 & 0 & 0 & 0.7801 \\
C & 0.9099 & 0.8249 & 0 & 0 & 0 \\
D & 0.8663 & 0 & 0 & 0.4226 & 0 \\
E & 0.9668 & 0.8952 & 0 & 0 & 0 \\
\hline
\end{tabular}

A:online community; B:Do the activities to close the People; C: traffic safety; D: Detected criminal cases; E: Improve the attitude of the service

Table 14. The degree of prominence and net causeleffect of barriers for experts.

\begin{tabular}{lllll}
\hline & $\mathbf{R}$ & $\mathbf{C}$ & $\mathbf{r}+\mathbf{c}$ & $\mathbf{r - c}$ \\
\hline A & 4.6055 & 4.6167 & 9.2222 & -0.0112 \\
B & 1.7288 & 2.7755 & 4.5043 & -1.0467 \\
C & 1.7348 & 0.9067 & 2.6415 & 0.8281 \\
D & 1.2889 & 1.1896 & 2.4785 & 0.0993 \\
E & 1.8620 & 1.7315 & 3.5935 & 0.1305 \\
Avg. & & & 4.4880 & \\
\hline
\end{tabular}

A:online community; B:Do the activities to close the People; C: traffic safety; D: Detected criminal cases; E: Improve the attitude of the service

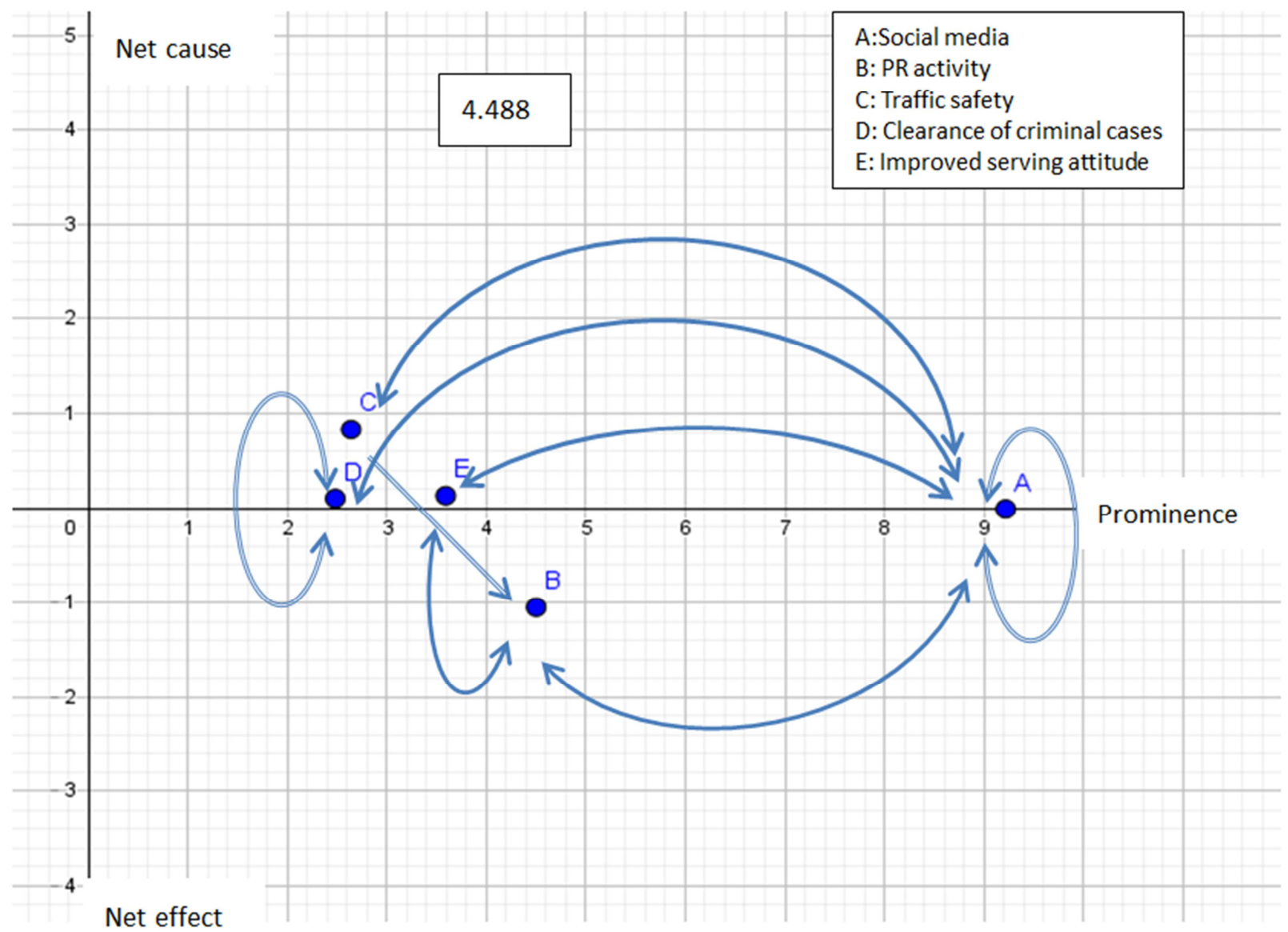

Figure 2. Overall DEMATEL prominence-causal relationship diagram.

\section{Analysis}

A system designer evaluates the relationship between sets of paired screens in terms of frequency and direction of mutual movements. $\mathrm{r}+\mathrm{c}$ represents the prominence. A high correlated relationship among criteria indicates that it is important in the process of elevating approval ratings. The $\mathrm{r}+\mathrm{c}$ value of social media and PR activity criteria is higher than the average $r+c$ value 4.4880 , indicating that those two criteria have more influence on the polling prominence than other criteria. Traffic safety, criminal case clearance and improved serving attitude criteria are on the left hand side of 
the average value, indicating that their influence on the polling prominence is smaller.

If the $r-c$ is the degree of causal relationship and it is negative, the effect in the causal relationship shifts towards net effects. This type of criteria tends to be influenced by other critypes of criteria. Any attempt to boost or elevate the polling prominence must focus on the origins that influence those criteria. If social media and PR activity criteria are negative, they are influenced by other three criteria. If $\mathrm{r}-\mathrm{c}$ is positive, this type of criteria is net causes, which is the cause in the causal relationship. As to the elevation of the polling result, this type of criteria has more room to be adjusted and traffic safety, criminal case clearance and improved serving attitude criteria belong to this type of criteria.

\section{Conclusion}

Based on the analysis derived from the above-mentioned information, which ones of the 5 criteria used to elevate polling results should be chosen or dumped in order to understand the core evaluation value? High criteria prominence indicates that it is important in the process of elevating polling results, and these criteria must be given more consideration, so it should do more on social media and PR activity criteria.

In addition, based on causal degree r-c, it may conclude that among those five criteria, social media and PR activity criteria belong to the affected criteria and they are respectively influenced by traffic safety, criminal case clearance and improved serving attitude criteria. Those three criteria have lower prominence in raising polling results, but they are tactics that belong to net causes. This means that these three tactics act as the foundation for the promotion of the preceding two tactics. However, it should be concluded that only when the foundation is well laid, the promotion effect can be achieved and a good polling result can be obtained

Besides doing analysis through prominence and causal degrees, the arrows in the causal diagram also contain important management ideas. From the causal diagram of the five criteria, it find the effect resulting from the interaction between social media criterion and other criteria. Criminal case clearance criterion has a one-way impact on PR activity criterion and may increase the topics and items of organized activities. PR activity criterion and improved serving attitude criterion may also interact with each other. Social media criterion and criminal case clearance criterion may have an impact on themselves.

To sum up the prominence, causal degrees, and arrow directions in the causal diagram, it would like to say that social media and PR activity criteria are important influence factors in raising the prominence of polling results. However, these two criteria belong to the affected criteria. Traffic safety, criminal case clearance and improved serving attitude tactics are three caused effects. These three tactics serve as the foundation of police work. Police departments should practically lay the foundation well and then use social media and PR activity tactics to make the public aware of their good performance. That will be the best way to elevate people's satisfaction with police work.

\section{References}

[1] Ming-Lang Tseng, A causal and effect decision making model of service quality expectation using grey-fuzzy DEMATEL approach, Expert Systems with Applications 36 (2009) 7738-7748.

[2] Hsiang-Chuan Liu, Wei-Sung Chen, Wei-Guang Tsaur, Hung-Ming Yeh, Chung-Ling Huh, An evaluation of the Balance and Variation of DEMATELs by Using Liu's Integrated Validity Index, Journal of Data Science 14(2016), 509-518.

[3] Liou, J. J. H., Yen, L. \& Tzeng, G. H. (2008), Building an effective safety management system for airlines, Journal of Air Transport Management, 14(1), 20-26.

[4] Ilker Gölcüka, b, Adil Baykaso glua, An analysis of DEMATEL approaches for criteria interaction handling within ANP, Expert Systems with Applications, Volume 46, 15 March 2016, Pages 346-366.

[5] Hsiao-Ming Chen, Chia-Huei Wu, Sang-Bing Tsai, Jian Yu, Jiangtao Wang and Yuxiang Zheng, Exploring key factors in online shopping with a hybrid model, Springer Plus (2016) 5:2046.

[6] Shinichiro Hori, Yujiro Shimizu, Designing Methods of Human Interface for Supervisory Control Systems, Control Engineering Practice, 7 (1999) (11), 1413-1419.

[7] Tamura, H., H. Okanishi, and K. Akazawa (2006), Decision Support for Extracting and Dissolving Consumers' Uneasiness Over Foods Using Stochastic DEMATEL, Journal of Telecommunications and Information Technology, 4, 91-95.

[8] Hsieh, Yi-Fang; Lee, Yu-Cheng; Lin, Shao-Bin, Rebuilding DEMATEL threshold value: an example of a food and beverage information system, Springer Plus ,Aug/22/2016 vol: 5:1385 P.1-13.

[9] Elham Falatoonitoosi, Zulkiflle Leman, Shahryar Sorooshian, Meysam Salimi, Decision-Making Trial and Evaluation Laboratory, Research Journal of Applied Sciences, Engineering and Technology(2013)5(13): 3476-3480.

[10] Mavi, Reza Kiani; Kazemi, Sajad; Najafabadi, All Fallahian, Identification and Assessment of Logistical Factors to Evaluate a Green Supplier Using the Fuzzy Logic DEMATEL Method, Polish Journal of Environmental Studies (2013) vol. 22( 2), 445-455.

[11] Ching-Lan Tsai, Using DEMATEL To Analysis of Decision-Making in Enterprise Cloud Migration Department, Taoyuan Innovation Journal (2015. Dec) No.35,311-330.

[12] Li-Hsing Hoa, Shu-Yun Feng b, Yu-Cheng Lee. Tieh-Min Yen, Using modified IPA to evaluate supplier's performance: Multiple regression analysis and DEMATEL approach, Expert Systems with Applications 39 (2012) 7 102-7109.

[13] Chih-Hsien Fan, Chih-Yao Shih, To construct the model of supplier of achievements by the Green Supplier Chain -Construct it by DEMATEL, Journal of Performance and Strategy Research, mar 2009, 6(1) 89-115. 
[14] Gwo-Tsuen Jou, Benjamin J. C. Yuan, Application of DEMATEL and ANP to the R\&D Project Selection, Sun Yat-Sen Management Review (2014.09), vol.22(3), p.543-572.
[15] Chunguang Bai, Joseph Sarkis, A grey-based DEMATEL model for evaluating business process Cross: Mark management critical success factors, Int, J. Production Economics 146 (2013) 281-292. 